\title{
Subject Stages Domain
}

National Cancer Institute

\section{Source}

National Cancer Institute. Subject Stages Domain. NCI Thesaurus. Code C95099.

A subject domain utilized for the submission of information encompassing and representing data, vocabulary or records related to subject stages. 